\title{
How Clinical Instructor Behavior Affects Student Clinical Engagement from a Motivational Perspective
}

\author{
Anthony W. Knight, CNMT, RT(N), FSNMMI-TS \\ Department of Radiology, University of Iowa Hospitals \& Clinics
}

\begin{abstract}
Given the close interpersonal nature of the student-clinical instructor $(\mathrm{Cl})$ relationship and the unpredictable and often stressful clinical environment in which they interact with one another, it is extremely important that Cls understand how their behavior directly affects their students' motivation to engage in educationally important clinical activities. This article presents a review of the motivation literature grounded in self-determination theory with the goal of providing the reader insight into how $\mathrm{Cl}$ psychologic need-supporting/thwarting behaviors affect student-Cl engagement. Specific need-supporting and needthwarting behaviors are identified and discussed in terms of how they impact students' needs for autonomy, competency, and relatedness. Recent research has revealed a strong connection between overall $\mathrm{Cl}$ need-supporting/thwarting behavior and student clinical engagement. The author hopes to bring further awareness of the powerful psychologic impact Cls have on their students and to draw attention to the need for routine in-service programs specifically designed to teach Cls how to effectively use psychologic need-supporting behaviors and avoid psychologic need-thwarting behaviors when working with their students.
\end{abstract}

Key Words: clinical instruction; student engagement; student motivation; Self-Determination Theory

J Nucl Med Technol 2018; 46:99-106

DOI: $10.2967 /$ jnmt.118.209320

$\mathbf{T}$ he impact an instructor can have on student learning and development can be profound (1-4). Umbach and Wawrzynski (5) suggest that instructors may play the single-most important role in student learning. This is especially true in health and medical education, where its practice-based clinical component has more in common with traditional apprenticeships than the college classroom. While on clinical rotations, students learn by doing the job. Their clinical instructors (CIs) teach while doing the job. Students routinely spend several full working days in close contact with their CI during any particular clinical assignment. Contrast this to the $2-3 \mathrm{~h}$ per week during which

\footnotetext{
Received Feb. 2, 2018; revision accepted Mar. 29, 2018.

For correspondence or reprints contact: Anthony Wayne Knight, University of lowa, 3834 JPP, Department of Radiology, University of lowa Hospitals \& Clinics, 200 Hawkins Dr., lowa City, IA 52242.

E-mail: anthony-knight@uiowa.edu

Published online May 3, 2018.

COPYRIGHT (c) 2018 by the Society of Nuclear Medicine and Molecular Imaging.
}

multiple students interact with a single instructor at the same time that is typical of most college classroom-based education. The fact that students and CIs spend so much more one-on-one time with each other would be enough to suggest that the nature and quality of the student-CI relationship takes on an increased level of significance in clinical education.

If one also takes into consideration the many unique situational factors that make the clinical learning environment foreign to students brought up in the classroom, one could certainly argue that the quality of the student-CI relationship is most likely the single-most important determinant of student success. It could also be argued that the burden of developing and maintaining this relationship should fall on the CIs because of their familiarity with the world of clinical practice and the degree of knowledge and skill one needs to be successful in it. In the clinical setting, the nature of the relationship between students and their CIs is a convoluted mix of role expectations. At various times the dynamic might be one of teacher-learner, supervisor-subordinate, expert-novice, coach-trainee, and mentor-mentee, and the switch between these roles can be swift and unsignaled (6). The complicated nature of the student-CI relationship, and the relatively long periods of time the student and instructor interact with one another in an often unpredictable and stress-filled environment, significantly amplifies the degree of student dependency on the instructor's ability to maintain a safe and effective learning environment.

This review of the educational research literature will specifically focus on examining how CI behaviors affect levels of student engagement in clinical activities from a motivational perspective (a point of view that this author believes is too often overlooked).

\section{THE UNIQUE NATURE OF CLINICAL EDUCATION}

The clinical environment is different from the traditional classroom in several significant and important ways (7). The setting is primarily designed to deliver patient care, and as such, is one characterized by variability, unpredictability, and a lack of continuity and consistency (8). Clinical learning opportunities tend to be unique and unstructured. They typically cannot be anticipated, manipulated, or repeated (9). The primary focus of the clinic is on the patient, not the student. Patient care and safety are 
always the first priorities. The education of neophyte practitioners is a secondary concern at best. Teaching and learning are expected to take place within the parameters of daily clinical operations without compromising the quality of patient care and the efficient running of the clinic. Students' learning opportunities are more dependent on the clinic workload and mix of scheduled patient procedures than on any kind of pedagogically predetermined sequencing (10). All the eccentricities of the clinical environment work against effective student learning and skill development, which generally thrive in controllable consistent, predictable repetitive settings at novice levels.

CIs are expected to effectively blend 2 occupations, clinical practitioner and teacher, often within the same resource constraints and reward systems afforded practitioners who do not have teaching responsibilities. CIs must serve 2 sets of clients simultaneously: their patients and their students. And although most CIs are typically well prepared to perform their clinical duties, few are formally prepared to teach $(11-15)$. Most CIs are hired as staff technologists because of their clinical expertise. Only rarely will any of these individuals have had formal training in teaching methodology, learning styles, or the effective evaluation of student learning and clinical performance. The faulty underlying assumption inherent in the practice of hiring expert practitioners to be teachers is the belief that competent clinicians, because of their job expertise, should be able to effectively facilitate students' learning of the appropriate knowledge, attitudes, and skills needed to become competent clinicians themselves. McKeachie (16) maintains that expertise in a particular discipline is not sufficient to ensure good teaching. Expert clinicians will not necessarily grow into expert CIs intuitively (6).

Not only are most CIs underprepared to teach, many are expected to teach without any regard for their desire to do so. Clinical sites are often chosen based on factors such as the convenience of the clinic's physical location or its administration's willingness to take students rather than on the quality of the teaching opportunities available or the instructional expertise of their clinical staff (12). CIs are usually assigned to this role by their supervisors, or some other authority figure, without any opportunity to decline (17). It is seen as a job requirement rather than an elective. So, unlike the classroom teacher who is typically both prepared and motivated to teach, many CIs may be neither.

The authenticity of the clinical component can be a strong source of motivation for students (18). Because learning takes place in the context of professional practice, students rarely question the relevance of what is to be learned (19). Students are also often motivated by the excitement of the clinical environment and the display of technical expertise and professionalism that the seasoned practitioners they observe model for them (20). It would appear that one could expect the motivation levels of the students beginning the clinical phase of their education to be extremely high. If this is indeed the case, it would seem that one of the primary objectives of the clinical educator would be to avoid doing anything that could possibly demotivate their students. If motivation is near peaked to begin with, there's only one direction it can go: down. Without a clear understanding of how their own behavior might affect their students' drive to succeed, unenlightened CIs are at risk of unintentionally impairing their students' professional development.

Ironically, formal assessments of current educational practice show that the addition of teaching responsibilities to a practitioner's job duties rarely comes with any opportunity to be properly educated on how to handle these additional obligations effectively $(11,13-15,20)$. And as a result, a significant and important portion of a student's professional education is routinely put in the hands of underprepared and perhaps unmotivated CIs who typically rely on their own lay-theories of education and motivation.

\section{AN ASSESSMENT OF THE CURRENT STATE OF CLINICAL INSTRUCTION FROM A MOTIVATIONAL PERSPECTIVE}

The findings of recent research clearly suggest the need for $\mathrm{CI}$ in-service education programs that serve to identify for attendees the specific behavioral guidelines that will help them become better educators in terms how they affect their students' motivation levels (21). This study, which examined the influence CIs have on their students' motivation to engage in educationally important clinical activities, found that more than $51 \%$ of the variance in students' engagement scores was directly related to how they were treated by their CIs. This finding may be especially surprising to the many who would assume that a student's own baseline motivation level is the most important determinant to how fully engaged a student is in the clinic, that if a student is disengaged and underperforming, it is all on the student. In this study of more than 750 CIs, the investigator found that $18 \%$ of the CIs evaluated had behavioral assessment scores placing them clearly in a range that identifies them as "demotivators" (22). These are individuals who students reported actually undermined their desire to engage in the clinical activities in which they knew full well they needed to participate to succeed. Students who evaluated demotivators reported working less hard, paying less attention, and often just acting as if they were doing something constructive, and generally felt more disappointed and frustrated than students who worked with CIs whose behavior they felt actually motivated them to do well.

If the findings of this quantitative multiprogram-multiinstitution-based study are indeed representative of the pool of CIs currently practicing in this country, having nearly a fifth of a profession's CIs behaving in ways that are counterproductive and contrary to its students' best interests is problematic to say the least and warrants the 


\section{SOCIO-CULTURAL INFLUENCES}

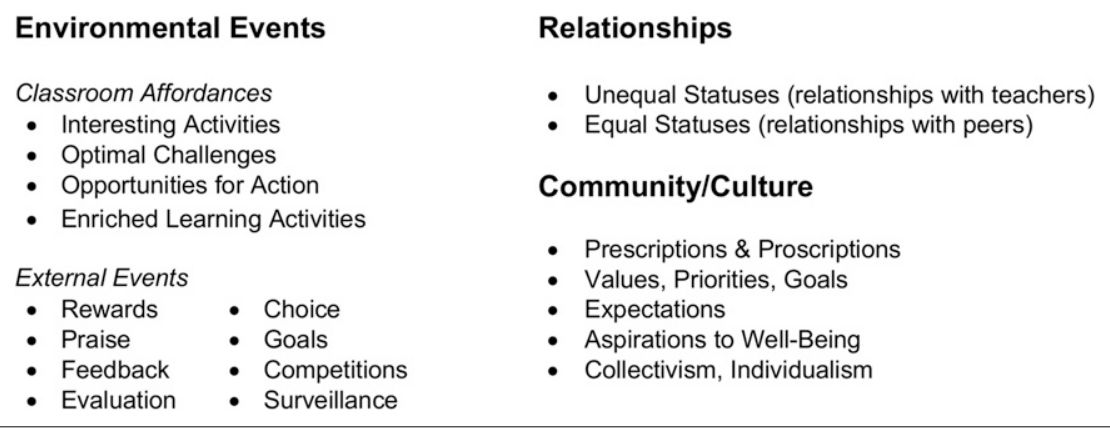

FIGURE 1. Social-cultural influences on student motivation, learning, and development (Adapted from (29).)

attention of health-care education program officials everywhere. It appears there is a great need for educational interventions (e.g., in-service programs) that specifically focus on the relationship between the quality of a Cl's interpersonal interactions with their students and their students' motivation to engage in educationally important clinical activities. The remaining sections of this article identify some of the principles and practices that would be appropriate to cover during such an education program.

\section{A USEFUL THEORETIC FRAMEWORK INFORMING EFFECTIVE CLINICAL INSTRUCTION}

Self-Determination Theory (SDT) has been a popular framework with which to study student motivation and engagement (23). The robustness of SDT and its ability to explain and predict the impact of teacher behaviors on important student outcomes suggest that it is a powerful framework on which to base not only educational research but also everyday practice. SDT is especially useful when studying the dynamics of the student-instructor relationship because of its emphasis on the internalization of attitudes and values. According to SDT, people seek to satisfy 3 basic psychologic needs: the need for autonomy, the need for competence, and the need for relatedness (24). Selfdetermination theorists contend that overall psychologic health and well-being requires the satisfaction of all 3 needs. The need for autonomy is defined as people's desire to have control over their own actions and to make their own choices. The need for relatedness is defined as the human striving for close personal relationships and having a sense of belonging. The need for competence refers to the desire to capably interact with one's environment and to bring about important outcomes and manage challenges (25). SDT postulates that the environment affects motivation through its influence on the individual's perception of autonomy, competence, and relatedness, which in turn, leads to consequences (26). Supporting a person's psychologic needs helps him or her internalize important values and perspectives and results in a shift from amotivation or controlled self-regulatory styles toward more self-deter- mined and satisfying forms of motivation. Frustrating or thwarting the satisfaction of psychologic needs tends to promote external regulation and amotivation (24). Recent research provides convincing support for this motivational sequence (27).

According to SDT, sociocultural context plays a significant role in the initiation and regulation of behavior (28). A person assigns meaning to various salient environmental factors, which in turn greatly influence his or her behavior. These attributions tend to either promote or thwart selfdetermined behavior. Figure 1 identifies some the sociocultural factors often used in the study of student motivation, learning, and development (29). Teachers are arguably the most potent influence in the sociocontextual mix because their position of authority gives them the power to manipulate, at least to some degree, all of the other factors listed on the table. Need-supportive teachers manipulate sociocontextual variables in such a way as to satisfy student needs for autonomy, competence, and relatedness, whereas need-thwarting teachers create an environment that prevents the fulfilment of those needs.

SDT-based research investigating the influence of teacher behaviors on student motivation has almost exclusively focused on the positive effects of psychologic needsupportive behaviors and interactions. Theorists group these behaviors into 3 clusters associated with each psychologic need: autonomy-support, competence-support, and relatedness-support $(19,30,31)$. Instructors can support a student's need for autonomy by creating opportunities for the student to take the initiative and make choices during learning activities that are designed around the student's own needs and interests. Autonomy-supportive instructors rely on noncontrolling language, clarify the relevance of the material or skills to be learned, and openly acknowledge the student's perspective and feelings (31). Autonomy-thwarting behaviors include the use of controlling language and directives, extrinsic sources of motivation (rewards and other contingencies), and blocks to any expressions of negative affect (31).

Research shows that autonomy-supportive teaching leads to better student outcomes in several important areas (30). When compared with students of controlling teachers, the students of autonomy-supportive teachers show higher academic achievement, greater conceptual understanding, more active information processing, greater flexibility in thinking, greater creativity, higher perceived competence, more positive emotionality, and higher self-esteem (30). The literature also documents the strong relationship between an instructor's autonomy-support and his or her student's self-determination. Self-determined students, in addition to being higher achievers, show a preference for, 


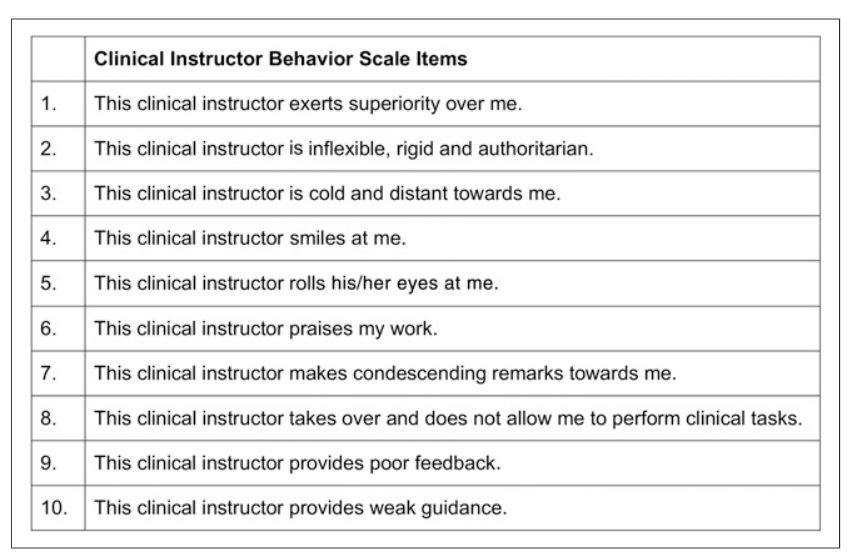

FIGURE 2. A rank order of the $10 \mathrm{Cl}$ behavior scale items that showed greatest group student engagement score differences between motivators and demotivators.

and get more pleasure from, optimal challenge, hold stronger perceptions of self-control, hold stronger psychosocial beliefs, are more empathetic and sensitive to people's psychologic and social needs, and behave in an autonomysupportive fashion with others (31).

An instructor can support a student's need for competence by providing structure (23). Structure refers to the amount and clarity of the information that teachers give students concerning expectations and ways of achieving the desired outcomes. Instructors provide structure by offering consistent guidance and direction during learning activities and by offering task-oriented and personal control-enhancing feedback (31). Competence-thwarting behaviors are characterized by the presence of a chaotic learning environment. Competence-thwarting instructors provide little or no structure for the students. They behave in ways that leave the student to their own resources. Their communication with the student is confusing or contradictory, and they often fail to clearly identify expectations or a means by which the student can obtain the instructional goals and objectives. An instructor is guilty of competence-thwarting when he or she offers learning activities that are not well thought out and forms of constructive feedback are either absent or ineffective.

Relatedness-support communicates psychologic availability and warmth and enhances interpersonal closeness (31). Relatedness-supportive teachers are viewed by students as being more positive and effective (32). Relatedness-support behaviors can be effectively divided into 2 subsets, verbal and nonverbal. Recognized nonverbal relatedness-supporting behaviors include smiling, eye contact, gesturing, vocal expressiveness, and relaxed body posture. Verbal relatedness-support is associated with verbal indications of humor, praise, self-disclosure, initiation, and inclusiveness (33). Wilson and Locker (33) found a low correlation between relatedness-supporting and teaching effectiveness behaviors. This gives credence to the claim that they are indeed separate constructs.
Relatedness-thwarting strategies overtly manipulate or exploit the student-instructor relationship (19). Any behaviors that demonstrate a lack of concern for the student's well-being and self-worth or show negative conditional regard work to undermine a student's feelings of relatedness. Intimidation, humiliation, embarrassment, ostracism, and rejection are hallmark signs of relatednessthwarting behavior.

In one of the aforementioned studies (22), the investigator found that most behavioral survey items that generated the greatest differences in student engagement scores when comparing CIs identified as motivators with those identified as demotivators were those associated with several very specific low-inference nonverbal behaviors that most people would likely consider unwelcoming and disenchanting. Figure 2 provides a listing, in rank order, of the 10 items that best separated motivators from demotivators.

According to SDT, engagement is the publicly observable outcome of private unobservable motivational processes (32). Engagement is the smoke to motivation's fire. If one wants to evaluate internal motivational processes, it is logical to measure the observable indicators of engagement as outcome variables. SDT also recognizes the concept of disaffection, which is seen as more than simply the absence of engagement. Disaffection refers to the presence of maladaptive behaviors and emotions. Disaffected students tend to withhold effort, give up easily, or resort to doing just enough to get by. They often feel burdened, controlled, frustrated, anxious, or angry. Experiences that satisfy one's psychologic needs for autonomy, competency, and relatedness tend to stimulate engagement and suppress disaffection. Experiences that impede the satisfaction of these 3 psychologic needs tend to do just the opposite.

Reeve believes, along with other prominent engagement scholars $(34,35)$, that student engagement fully mediates the motivation-to-achievement relationship, that the observed direct effects of motivation on student achievement disappear when engagement is considered a predictor of positive outcomes (36). The implication is that there can be no other positive student outcomes without at least some degree of student engagement. If this is indeed the case, a valid measure of student engagement might be the single most powerful predictor of student success. Reeve (34) also believes that one of the reasons student engagement is important is because it is "a malleable student characteristic that is unusually open to constructive influences, such as teacher support" (p. 162). The malleable nature of engagement only adds to its usefulness for informing educational practice. When educators understand what kinds of variables affect student engagement, and learn how to effectively manipulate the variables under their control, they will be much more likely to facilitate student learning and development.

Factors that affect student motivation have been well established in the SDT literature (34). If engagement is the external manifestation of internal motivational processes, 
it logically follows that what affects student motivation affects student engagement. Reeve maintains that engagement arises from the same types of experiences that are believed to increase intrinsic motivation, experiences where students' psychologic needs are being met. Thus, instructors can increase student engagement by nurturing students' needs for autonomy by providing autonomy support, their needs for competence by providing structure, and their needs for relatedness by providing interpersonal involvement.

Research has shown that instructor psychologic need support can indeed affect student engagement (37). For instance, studies have found that teachers' reports of the quality of the student-teacher relationship predicted levels of observed student engagement $(38,39)$. Additionally, it has been shown that teachers who create respectful and socially supportive environments while providing students with challenging work promote student engagement (38).

\section{HOW TO EFFECTIVELY MOTIVATE AND ENGAGE STUDENTS}

Reeve (23) maintains that the SDT research literature clearly supports the claim that teachers are by far the most powerful influences on student motivation at the contextual level of education and as such, may be even more powerful at the less stable situational level. Reeve has identified the teacher-created contextual elements that SDT research has found nurture students' basic psychologic needs. Students' need for autonomy is nurtured by teacher behaviors that allow for student choice and freedom to take the initiative. Students' need for competence is nurtured by teacher-provided structure. Their need for relatedness is nurtured by interpersonal involvement.

\section{Autonomy and Autonomy-Support}

The benefits to the student of being autonomously motivated (i.e., self-regulated rather than externally regulated) have been well documented in the SDT literature. Autonomy-supportive teacher behaviors, by definition, help students to become more autonomously motivated. Autonomy-supportive teachers create opportunities for students to take initiative in their learning by providing instruction based on students' interests, preferences, personal goals, and sense of challenge and curiosity while also allowing them opportunities to make choices and direct their own behavior (31). Controlling teachers, on the other hand, thwart students' need of autonomy by building instruction around incentives, directions, consequences, and deadlines (i.e., external forms of motivation). The students of autonomy-supportive teachers have been found to have, on average, higher academic achievement, higher perceived competence and feeling of self-worth, more positive emotionality, greater creativity, and higher retention rates $(23,30)$. Additionally, students of autonomy-supportive teachers showed greater conceptual under- standing, greater flexibility in thinking, and more active information processing than students who had controlling teachers (23).

Reeve et al. (30) found that, although controlling teachers talked as much as autonomy-supportive teachers, autonomy-supportive teachers listened significantly more. They also found that controlling teachers spent more time holding instruction materials (rather than allowing students to do so), gave students less time for independent work, and gave students more solutions than autonomy-supportive teachers. Raters reported that controlling teachers used more directives and gave more commands whereas autonomy-supportive teachers used more empathic perspective-taking statements, praised mastery, and avoided criticism.

In a follow-up study, Reeve and Jang (40) found that students' perceived autonomy was positively correlated to certain teacher behaviors including spending time listening to their students, setting aside time for independent work, providing students opportunities to talk, praising signs of improvement and mastery, encouraging student effort, offering progress-enabling hints when students became stuck, responding to student questions and comments, and acknowledging the student's perspective and experiences. Those teacher behaviors that correlated negatively with perceived autonomy and were identified as autonomythwarting included monopolizing learning materials, providing worked-out solutions and answers before the student had time to work on the task independently, directly telling the student the correct response instead of allowing him or her the time and opportunity to discover it, uttering directives and commands, introjecting "should" or "got to" statements within the flow of the instruction, and using controlling questions as a way of directing the students' work.

Only a few SDT-based studies investigating the impact of instructor behavior on students have been situated in either true or simulated clinical learning environments. In one, Williams and Deci (41) looked at medical students enrolled in medical interviewing courses in 2 U.S. medical schools. As hypothesized, the students of instructors who scored higher in autonomy-support were more autonomously motivated, more interested in patient interviewing, had higher perceived competence, and reported psychosocial (i.e., humanistic patient-centered) rather than biomedical (i.e., mechanistic disease-oriented) beliefs. The data, collected 1-2 y after the completion of these courses, showed the effects to be lasting. They also showed that the students of autonomy-supportive instructors tended to be more autonomy-supportive with their patients themselves. The evidence showing the connection between the internalization of psychosocial beliefs and autonomy-supportive interpersonal interactions suggests that SDT is indeed an appropriate framework for studying clinical education because the adoption of humanistic professional values and attitudes 


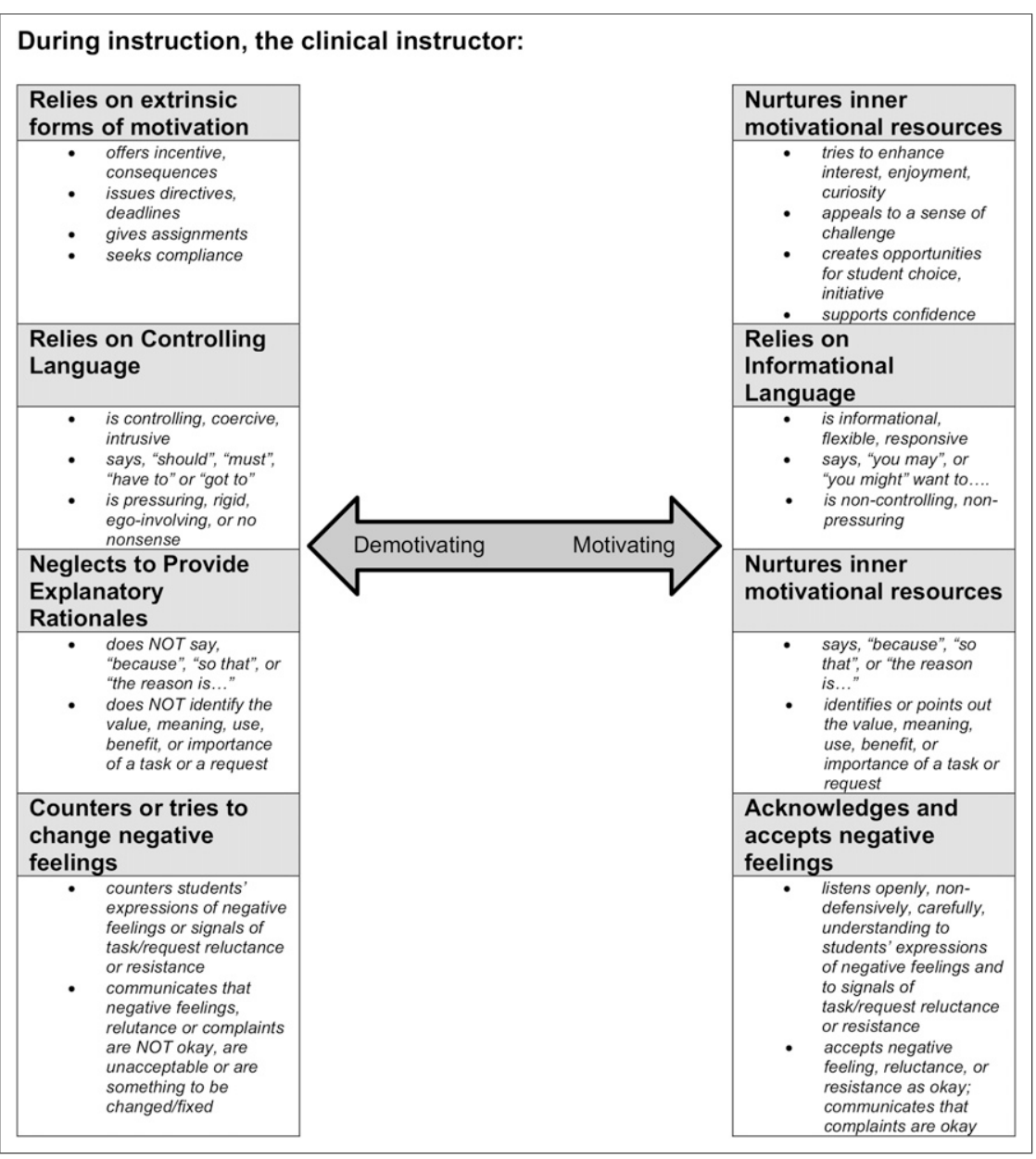

FIGURE 3. Behaviors that support or thwart students' need for autonomy (36).

\section{Competency and \\ Competency-Support}

Teachers nurture a student's need of competence by providing structure and quality task-oriented informational feedback (23). Structure refers to the amount and clarity of information that teachers give students about learning/ developmental expectations and ways of achieving desired outcomes. Teachers build structure by providing consistent guidance and direction and by offering task-specific and autonomyenhancing feedback (31). They provide a program of action by scheduling learning activities using an informed understanding of the appropriate sequencing of these activities and mark the boundaries and manage the transition between these activities. They also provide stepby-step instruction when needed.

A lack of structure leaves students to their own, often inadequate, resources. According to SDT, this lack of instructor-provided structure will likely lead to lower levels of perceived student competence and a perceived lack of control over important outcomes. Instructor behaviors that actually promote chaos would likely thwart students' need for competency, leading to high levels of frustration and dissatisfaction. Instructors can create a chaotic learning environment by asking for outcomes without providing any guidance on how to achieve them, using ambiguous, confusing, contradictory, or misguiding directions, and by providing mistimed or inaccurate taskoriented feedback. Relative to students with chaotic teachers, students whose teachers effectively provide structure tend to have more positive outcomes including enhanced engagement (38) and higher levels of self-regulation (42).

Structure is not established, as many believe, by making demands; imposing rigid rules; or establishing sanctions for mistakes, failure, or disengagement (23). This understanding of structure would actually lead to behaviors that thwart a student's need for autonomy and, in turn, undermine student engagement and learning. Some of the specific behaviors that either support or thwart students' need of competency are listed in Figure 4.

FIGURE 4. Behaviors that support or thwart students' need for competency (36). 


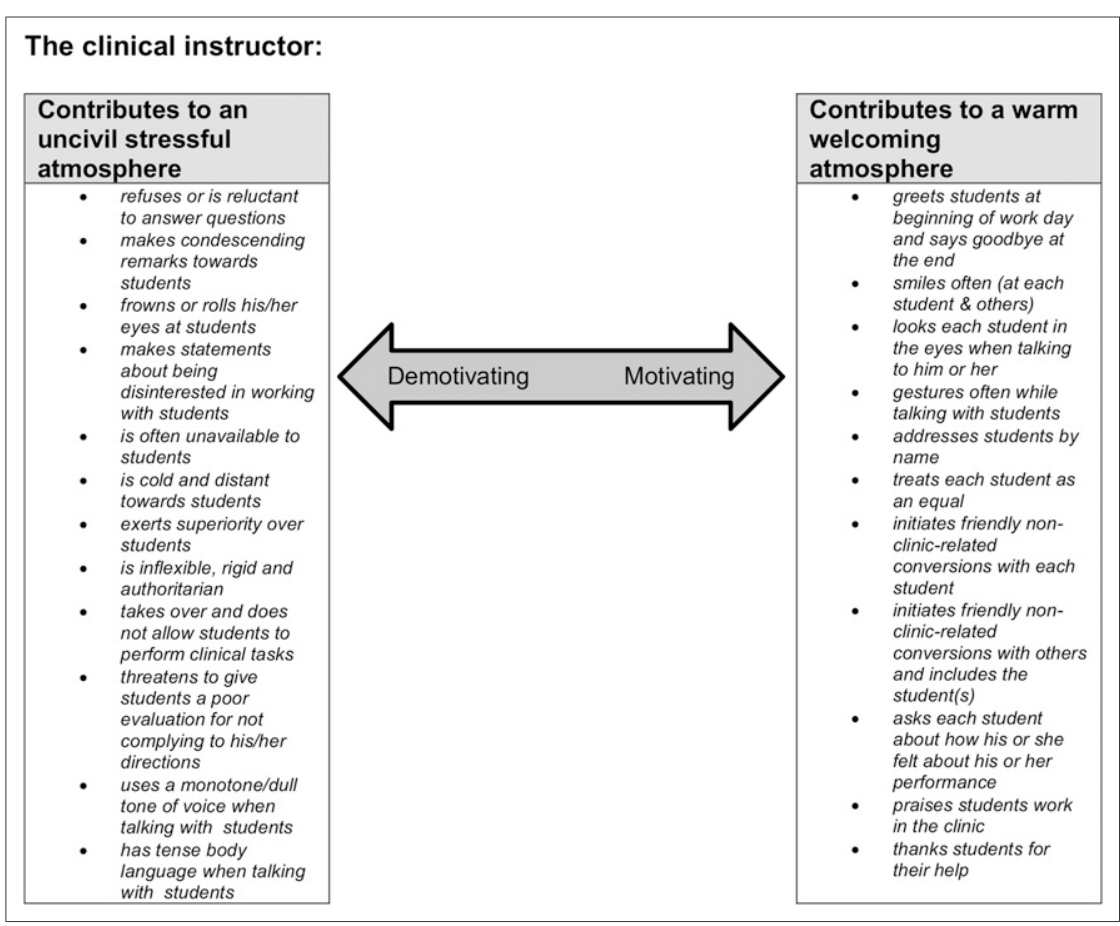

FIGURE 5. Behaviors that support or thwart students' need for relatedness $(33,46)$. out of the clinical learning environment. For instance, because of the unique nature of this relationship, it would not be uncommon to observe students in the clinical phase of their education going on a break or lunch with their CIs or even socializing outside work, doing things such as working out or playing on the same softball team together. This unusually tight social connection between student and CI only serves to elevate the importance of relatednesssupporting behaviors in terms of their ability to motivate and engage students. Figure 5 lists relatedness-supporting and relatedness-thwarting behaviors.

\section{CONCLUSION}

The evidence found in the research literature associated with effective and ineffective clinical teaching clearly underscores the importance of quality student-instructor relationships and the effect they can have on student educational outcomes. More specifically, studies grounded in SDT have determined that students are significantly affected by the psychologic need-supporting or need-thwarting behaviors of their supervising CIs. It would, thus, seem that specifically educating CIs on what types of behaviors support and thwart students' psychologic needs for autonomy, competency, and relatedness would be imperative for any and all clinically oriented educational programs. In-service programs can be effective and do not need to be terribly lengthy or cumbersome to deliver.

In a perfect world, all CIs would strive to consistently treat their students in ways that serve to motivate them to try harder and perform better than they would if left to their own devices. They would also refrain from ever behaving toward their students in ways that serve to demotivate them and "crush their spirit." Educational programs that provide opportunities for their clinical instruction faculty and staff to learn about, study, practice, and adopt the motivational principles and motivating behaviors identified in this brief review of the literature can rest assured that their people are doing their part in trying to bring the state of clinical education closer to reaching that ideal.

\section{DISCLOSURE}

No potential conflict of interest relevant to this article was reported.

\section{REFERENCES}

1. Chickering AW, Gamson ZF. Seven principles for good practice in undergraduate education. AAHE Bulletin. 1987;39:3-7.

2. Endo JJ, Harpel RL. The effect of student-faculty interaction on students educational outcomes. Res High Educ. 1982;16:115-138.

likely to interact socially on a personal level in and 
3. Feldman KA. The superior college teacher from the students' view. Res High Educ. 1976;5:243-288.

4. Pascarella ET, Terenzini P. How College Affects Students: Findings and Insights from Twenty Years of Research. San Francisco, CA: Jossey-Bass; 1991.

5. Umbach PD, Wawrzynski MR. Faculty do matter: the role of college faculty in student learning and engagement. Res High Educ. 2005;46:153-184.

6. Rounds L. A North American perspective on clinical supervision. In: Cutcliffe J, Butterworth T, Proctor B, eds. Fundamental Themes in Clinical Supervision. London, U.K.: Routledge; 2001:303-315.

7. Williams PL, Webb C. Clinical supervision skills: a Delphi and critical incident technique study. Med Teach. 2009;16:139-157.

8. Huggett KN, Warrier R, Maio A. Early learner perceptions of the attributes of effective preceptors. Adv in Health Sci Educ. 2008;13:649-658.

9. Werb SB, Matear DW. Implementing evidence-based practice in undergraduate teaching clinics: a systematic review and recommendations. J Dent Educ. 2004;68:995-1003.

10. Stalmeijer RE, Dolmans DH, Wolfhagen IH, Muijtjens AM, Scherpbier AJ. The development of an instrument for evaluating clinical teachers: involving stakeholders to determine content validity. Med Teach. 2008;30:e272-e277.

11. Belinsky SB, Tataronis GR. Past experiences of the clinical instructor and current attitudes toward evaluation of students. J Allied Health. 2007;36:11-16.

12. Giordano S. Improving clinical instruction: comparison of literature. Radiol Technol. 2008;79:289-296.

13. Ingrassia JM. Effective radiography clinical instructor characteristics. Radiol Technol. 2011;82:409-420.

14. Levy LS, Sexton P, Willeford KS, et al. Clinical instructor characteristics, behaviors and skills in allied health care settings: a literature review. Athl Train Ed J. 2009;4:8-13.

15. Steves AM. Improving the clinical instruction of student technologists. $J$ Nucl Med Technol. 2005;33:205-209.

16. McKeachie WJ. McKeachie's Teaching Tips: Strategies, Research and Theory for College and University Teachers. 11th ed. Boston, MA: Houghton-Mifflin; 1960.

17. Usher K, Nolan C, Reser P, Owens J, Tollefson J. An exploration of the preceptor role: preceptors' perceptions of benefits, rewards, supports and commitment to the preceptor role. J Adv Nurs. 1999;29:506-514.

18. Spencer J. Learning and teaching in the clinical environment: ABCs of learning and teaching in medicine. Br Med J. 2003;326:591-594.

19. Assor A, Kaplan H, Roth G. Choice is good, but relevance is excellent: autonomy-enhancing and suppressing teacher behaviors predicting students' engagement in schoolwork. Br J Educ Psychol. 2002;72:261-278.

20. Grimaudo NJ. Students' and Patients' Perspectives of Clinical Teaching at a Dental School [doctoral dissertation]. Gainesville, FL: University of Florida; 2007. Retrieved from ProQuest Dissertations and Theses (3300741).

21. Knight AW. Self-Determination Theory-Based Analysis of the Effects of Clinical Instructor Behavior on Student Clinical Engagement [doctoral dissertation]. Iowa City, IA: University of Iowa; 2016.

22. Knight AW. How clinical instructor behavior affects student clinical engagement. Oral presentation at: Annual Meeting of the Society of Nuclear Medicine and Molecular Imaging; June 10, 2017; Denver, CO.

23. Reeve J. Self-determination theory applied to educational settings. In Deci EL, Ryan RM, eds. Handbook of Self-Determination Research. Rochester, NY: University of Rochester Press; 2002:183-203.

24. Deci EL, Ryan RM. Handbook of Self-Determination Research. Rochester, NY: University of Rochester Press; 2002.

25. Deci EL, Ryan RM. The "what" and "why" of goal pursuits: human needs and the self-determination of behavior. Psychol Inq. 2000;11:319-338.
26. Vallerand RJ, Fortier MS, Guay F. Self-determination and persistence in a reallife setting: toward a motivational model of high school dropout. J Pers Soc Psychol. 1997;72:1161-1176.

27. Grouzet RM, Vallerand RJ, Thill EE, Provencher PJ. From environmental factors to outcomes: a test of an integrated motivational sequence. Motiv Emot. 2004;28:331-346.

28. Deci EL, Ryan RM. The support of autonomy and the control of behavior. J Pers Soc Psychol. 1987;53:1024-1037.

29. Reeve J, Deci EL, Ryan RM. Self-determination theory: a dialectical framework for understanding sociocultural influences on student motivation. In McInerney DM, Etten SV, eds. Big Theories Revisited: Volume 4 in Research on Sociocultural Influences on Motivation and Learning. Greenwich, CT: Information Age Publishing; 2004:31-60.

30. Reeve J, Bolt E, Cai Y. Autonomy-supportive teachers: how they teach and motivate students. J Educ Psychol. 1999;91:537-548.

31. Jang H, Reeve J, Deci EL. Engaging students in learning activities: it is not autonomy support or structure but autonomy support and structure. J Educ Psychol. 2010;102:588-600.

32. Reeve J, Jang H, Carrell D, Jeon S, Barch J. Enhancing students' engagement by increasing teachers' autonomy support. Motiv Emot. 2004;28:147-169.

33. Wilson JH, Locker L. Immediacy scale represents four factors; nonverbal and verbal components predict student outcomes. J Classr Interact. 2007;42:4-10.

34. Reeve J. A self-determination theory perspective on student engagement. In: Christenson SL, Reschly W, eds. Handbook of Research on Student Engagement. New York, NY: Springer Science Business Media, LLC; 2012: 149-172.

35. Skinner E, Furrer C, Marchand G, Kindermann T. Engagement and disaffection in the classroom: part of a larger motivational dynamic? J Educ Psychol. 2008;100:765-781.

36. Reeve J, Tseng CM. Agency as a fourth aspect of students' engagement during learning activities. Contemp Educ Psychol. 2011;36:257-267.

37. Fredricks JA, Blumenfeld PC, Paris AH. School engagement: potential of the concept, state of the evidence. Review Ed Res. 2004;74: 59-109.

38. Skinner EA, Belmont MJ. Motivation in the classroom: reciprocal effects of teacher behavior and student engagement across the school year. J Educ Psychol. 1993;85:571-581.

39. Blumenfeld PC, Puro P, Mergendoller JR. Translating motivation into thoughtfulness. In: Marshall H, ed. Redefining Student Learning. Norwood, NJ: Ablex; 1992:207-241.

40. Reeve J, Jang H. What teachers say and do to support students' autonomy during learning activities. J Educ Psychol. 2006;98:209-218.

41. Williams GC, Deci EL. Internalization of biopsychosocial values by medical students: a test of self-determination theory. J Pers Soc Psychol. 1996;70:767-779.

42. Sierens E, Vansteenkiste M, Goossens L, Soenens B, Dochy F. The synergistic relationship of perceived autonomy support and structure in the prediction of self-regulated learning. Br J Educ Psychol. 2009;79:57-68.

43. Furrer C, Skinner E. Sense of relatedness as a factor in children's academic engagement and performance. J Educ Psychol. 2003;95:148-162.

44. Birch SH, Ladd GW. The teacher-student relationship and children's early school adjustment. J Sch Psychol. 1997;35:61-79.

45. Wentzel KR. Social relationships and motivation in middle school: the role of parents, teachers, and peers. J Educ Psychol. 1998;90:202-209.

46. Beck JW. Deconstructing Student Perceptions of Incivility in the Nursing Education Triad [doctoral dissertation]. Baton Rouge, LA: Louisiana State University; 2009. 